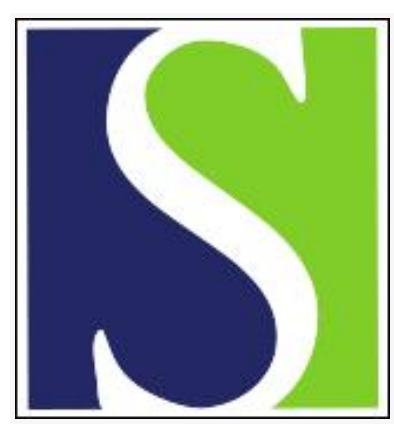

Scand J Work Environ Health 2007;33(2):140-147

https://doi.org/10.5271/sjweh.1117

Issue date: 31 Apr 2007

Operating room nursing and lung cancer risk in a cohort of female registered nurses

by Gates MA, Feskanich D, Speizer FE, Hankinson SE

Affiliation: Channing Laboratory, Third Floor, 181 Longwood Avenue, Boston, MA 02115, USA. mgates@hsph.harvard.edu

Key terms: cohort study; electrocautery; laser surgery; lung cancer risk; occupational hazard; operating room nurse; prospective study; registered nurse; surgical smoke

This article in PubMed: www.ncbi.nlm.nih.gov/pubmed/17460802

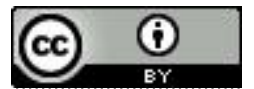




\title{
Operating room nursing and lung cancer risk in a cohort of female registered nurses
}

\author{
by Margaret A Gates, BS, ${ }^{1,2}$ Diane Feskanich, ScD, ${ }^{1}$ Frank E Speizer, MD, 1,3 Susan E Hankinson, $S c D^{1,2}$
}

\begin{abstract}
Gates MA, Feskanich D, Speizer FE, Hankinson SE. Operating room nursing and lung cancer risk in a cohort of female registered nurses. Scand J Work Environ Health 2007;33(2):140-147.

Objectives Smoke generated during laser surgery and electrocautery contains respiratory irritants and human carcinogens. Although laboratory and animal studies have demonstrated that this smoke has inflammatory and mutagenic potential, no population-based studies of the health effects of exposure to surgical smoke have been published. We examined the association between duration of employment as an operating room nurse, a proxy measure for surgical smoke exposure, and subsequent lung cancer risk.

Methods This study was conducted among 86747 women in the Nurses' Health Study. Information on the duration of prior operating room employment was collected in 1984, and the women were followed for incident, confirmed lung cancer. Cox proportional hazards regression was used to model the incidence rate ratio of lung cancer for each exposure category using women with no prior operating room employment for comparison. All of the models were adjusted for age, smoking history, passive smoke exposure, fruit and vegetable consumption, and alpha carotene and lycopene intake.

Results A history of operating room employment was not associated with an increased rate of lung cancer in multivariable analyses [rate ratio (RR) $0.99,95 \%$ confidence interval $(95 \% \mathrm{CI}) 0.86-1.15$ ]. In fact, nurses in the highest exposure category, $\geq 15$ years of operating room employment, had a significantly lower rate of lung cancer than nurses with no prior operating room employment (RR $0.58,95 \%$ CI $0.37-0.91$ ), possibly due to confounding by overall health status or residual confounding by smoking history.

Conclusions Long-term exposure to surgical smoke, as measured by the duration of operating room employment, does not appear to increase the risk of lung cancer.
\end{abstract}

Key terms electrocautery; laser surgery; occupational hazard; prospective; surgical smoke.

Laser surgery and electrocautery generate a visible, acrid smoke that contains numerous chemicals, including respiratory irritants and known and potential human carcinogens (1-3). These surgical procedures are in widespread use in operating and medical examination rooms, and knowledge of the chemical composition of surgical smoke has led to concern over the potential long-term occupational health hazards of exposure to surgical smoke. While patients are at risk of adverse events due to exposure to surgical smoke, particularly during laparoscopic procedures (4-8), the possibility of chronic health problems due to such exposure may be greatest for physicians, nurses, and other operating room personnel who repeatedly inhale surgical smoke.
The Occupational Safety \& Health Administration (OSHA) in the United States (US) estimates that 500000 US workers are exposed to surgical smoke annually (9), and many health care professionals are exposed several hours a day for periods of years or even decades. Standard surgical masks do not adequately filter surgical smoke particles (10-12). The US National Institute for Occupational Safety and Health (NIOSH) recommends the use of smoke evacuation and filtering systems during smoke-producing surgical procedures to minimize exposure to surgical smoke (13). However, even with the use of these systems, the potential for exposure remains. The level of exposure is dependent on multiple factors, including the surgical procedure

1 Channing Laboratory, Department of Medicine, Brigham and Women's Hospital and Harvard Medical School, Boston, Massachusetts, United States.

2 Department of Epidemiology, Harvard School of Public Health, Boston, Massachusetts, United States.

3 Department of Environmental Health, Harvard School of Public Health, Boston, Massachusetts, United States.

Reprint requests to: Margaret A Gates, Channing Laboratory, Third Floor, 181 Longwood Avenue, Boston, MA 02115, USA. [E-mail: mgates@hsph.harvard.edu] 
performed, the type of smoke removal device used, and the positioning of the smoke evacuator $(14,15)$.

Laboratory and animal studies indicate that surgical smoke has mutagenic potential and can induce inflammatory pulmonary changes in animals after repeated exposure (16-21). On the basis of an in vitro assay, Tomita et al (16) estimated that the smoke produced during laser irradiation or electrocauterization of 1 gram of tissue is equivalent to three to six cigarettes in mutagenic potential. Potentially harmful chemical compounds identified in surgical smoke include benzene, formaldehyde, toluene, acrolein, and polycyclic aromatic hydrocarbons (PAH) $(1,3)$. Although the results of laboratory and animal studies suggest the possibility that repeated exposure to surgical smoke may cause pulmonary problems in humans, no population-based studies of the health effects of long-term surgical smoke exposure have been published. We therefore examined the association between reported employment as an operating room nurse, a proxy measure for exposure to surgical smoke, and the incidence of lung cancer among women in the Nurses' Health Study cohort.

\section{Study population and methods}

In 1976, 121700 female registered nurses aged 30 to 55 years responded to a mailed questionnaire about known and suspected risk factors for cancer and heart disease, leading to the establishment of the Nurses' Health Study. The study participants completed followup questionnaires every 2 years, providing additional information about health outcomes and risk factors for disease. Between 1976 and 2000, the percentage of follow-up information obtained from the study participants (questionnaire responses plus deaths), out of all possible follow-up, was 95.6\%. The 1982, 1984, and 1992 questionnaires included questions about past or current work in an operating room. In 1982, we requested current employment status, with operating room nursing as one option. In 1984, we asked for the total number of years of regular work in an operating room, excluding time during training, with options of none, $<1$ year, $1-4$ years, 5-9 years, 10 -14 years, and $\geq 15$ years. In 1992, we requested current work status, with options including full-time operating room nursing and part-time operating room nursing.

In this analysis, the primary exposure of interest was the number of years of prior operating room work reported in 1984, which we used as a proxy measure for the amount of exposure to surgical smoke. Secondary exposure classifications included dichotomous variables for any prior operating room work reported in 1984, current operating room work reported in 1982, current operating room work reported in 1992, and any history of operating room work reported on one of the three questionnaires. The follow-up period of interest began on the return date of the questionnaire with the earliest relevant information on prior or current operating room work (1982, 1984, or 1992, depending on the analysis). The follow-up period ended on the date of lung cancer diagnosis, the return date of the last questionnaire prior to the diagnosis of any other cancer (excluding nonmelanoma skin cancer), the date of death, or June 2000, whichever came first. We excluded women who were missing data on operating room work on the 1984 questionnaire, as well as women with a diagnosis of cancer other than nonmelanoma skin cancer prior to 1984. After these exclusions, there were 86747 study participants included in the primary analysis.

The outcome of interest in the primary analysis was lung cancer diagnosed between the return date of the 1984 questionnaire and the end of the follow-up. We collected information on new diagnoses of lung cancer on each biennial questionnaire. For all reported lung cancer diagnoses, as well as deaths due to lung cancer identified through family members, the National Death Index, or the US Postal Service, researchers of the Nurses' Health Study contacted the study participants or their families to request permission to obtain pathology reports and other medical records related to the diagnosis. An estimated $98 \%$ of all deaths in the Nurses' Health Study cohort were captured through the National Death Index $(22,23)$. We confirmed cases by reviewing medical records whenever possible and otherwise by obtaining written or verbal confirmation from the study participants or death certificate information. There were 1041 incident lung cancer diagnoses reported between 1984 and 2000, and we obtained medical records for 903 diagnoses (86.7\%). Of these, we confirmed $753(83.4 \%)$ as primary lung cancers, we rejected $137(15.2 \%)$ as metastases from other sites, and we rejected $13(1.4 \%)$ as incorrect diagnoses. Of the 138 diagnoses for which we were unable to obtain medical records, we included in our analysis 48 diagnoses confirmed by the study participant (due to the high reliability of self-reported lung cancer in this cohort) and 58 diagnoses confirmed by death certificate information. The primary analysis included 859 cases of lung cancer, with $87.7 \%$ confirmed by medical record review. The 753 cases confirmed by medical records were also classified by histologic type, $16.6 \%$ being epidermoid or squamous, $16.9 \%$ being small cell, $48.7 \%$ being adenocarcinoma, $6.5 \%$ being large cell, $5.3 \%$ being combined epidermoid and adenocarcinoma, $2 \%$ being carcinoid, and $4 \%$ being of other histologic types.

We evaluated several covariates as potential confounding variables, including age, current exposure to passive cigarette smoke at home or work (reported in 
1982), and updated information on smoking history, body mass index $\left(\mathrm{kg} / \mathrm{m}^{2}\right)$, physical activity, intake of carotenoids, vitamin $\mathrm{C}$, vitamin $\mathrm{E}$, alcohol and total fat, and the frequency of consumption of whole milk, fruits and vegetables. We adjusted for smoking history by including the following variables together in the same statistical model: smoking status (current, past, never), years since quitting for past smokers $(<5,5-14$, or $\geq 15$ years), cigarettes per day for current smokers (1-4, 5-14, 15-24, 25-34, 35-44, or $\geq 45$ cigarettes), and age of smoking onset in years. In a separate model, we used smoking status, pack-years of smoking, and age of smoking onset to adjust for smoking history, to assess an alternative method of controlling for smoking. When adjusting for body mass index (BMI), we used the reported value from 2 years prior, to ensure that changes in BMI due to undiagnosed lung cancer did not affect the results. We collected dietary and nutrient information in 1984, 1986, 1990, 1994, and 1998 using a semiquantitative food-frequency questionnaire. Salvini et al (24) and Michaud et al (25) have previously described validation studies of the food-frequency questionnaire for this cohort. Adjustment for the dietary and nutrient variables used quintiles of intake, and we adjusted the intake values for total energy intake when appropriate.

We adjusted all models for age, smoking history, passive cigarette smoke exposure at home or work, quintiles of fruit and vegetable consumption, and quintiles of energy-adjusted alpha carotene and lycopene intake. After adjustment for age and smoking history, none of the other variables examined were significant confounders. However, we included additional covariates in the models due to evidence of the potential for confounding by these variables. We included fruit and vegetable consumption, alpha carotene intake, and lycopene intake in the models because previously published results showed an association between these variables and lung cancer in this cohort $(26,27)$. In addition, we included passive smoke exposure at home and at work in the models because of the variability in the distribution of these variables across exposure categories (table 1). Although the nurses with a longer duration of operating room employment were more likely to report regular exposure to passive cigarette smoke in 1982, particularly in the work environment, adjusting for passive smoke exposure did not change our results after control for age and personal smoking history.

We used time-dependent Cox proportional hazards regression to model the age- and multivariable-adjusted rate ratio for lung cancer among nurses with prior employment in an operating room, as compared with nurses with no prior operating room employment (28). We used the Anderson-Gill data structure, with a separate data record for each 2-year follow-up period during which the study participant was at risk of lung cancer, to handle time-varying covariates efficiently (29). We modeled age and age of smoking onset as continuous variables, and we used indicator variables to model all other potential confounding variables and the exposure variables. We also tested for a linear trend across categories of duration of operating room employment by modeling a continuous variable weighted by the midpoint of each duration category.

If covariate information was available from multiple questionnaire cycles, we updated the covariate value for each participant at the start of each 2-year follow-up cycle. During any one follow-up cycle, the proportion of women with missing covariate data was $12-13 \%$ for fruit and vegetable consumption, 3-13\% for alpha carotene and lycopene intake, $1-2 \%$ for age of smoking onset, and $4-8 \%$ for smoking status. For passive exposure to cigarette smoke, which was collected only in 1982, 20\% of the women in our analysis was missing data on exposure at home and $24 \%$ was missing data

Table 1. Baseline characteristics by number of years of operating room work reported in 1984 among 86747 women in the Nurses' Health Study cohort. ${ }^{\mathrm{a}}$

\begin{tabular}{|c|c|c|c|c|c|c|c|c|c|c|c|c|c|c|c|}
\hline \multirow{2}{*}{$\begin{array}{l}\text { Duration } \\
\text { of operating } \\
\text { room work } \\
\text { (years) }\end{array}$} & \multirow[t]{2}{*}{$\begin{array}{l}\text { Number } \\
\text { of } \\
\text { women }\end{array}$} & \multirow[t]{2}{*}{$\begin{array}{c}\text { Age } \\
\text { (years) }\end{array}$} & \multicolumn{3}{|c|}{$\begin{array}{l}\text { Smoking } \\
\text { status (\%) }\end{array}$} & \multicolumn{2}{|c|}{$\begin{array}{l}\text { Cigarettes } \\
\text { per day }(\%)^{\mathrm{b}}\end{array}$} & \multirow{2}{*}{$\begin{array}{l}\text { Months } \\
\text { since } \\
\text { quit- } \\
\text { ting }^{c}\end{array}$} & \multirow{2}{*}{$\begin{array}{c}\text { Age at } \\
\text { start of } \\
\text { smoking } \\
\text { (years) }\end{array}$} & \multicolumn{2}{|c|}{$\begin{array}{l}\text { Regular pass- } \\
\text { ive smoke ex- } \\
\text { posure }(\%)^{d}\end{array}$} & \multicolumn{2}{|c|}{$\begin{array}{l}\text { Fruit \& vegetable } \\
\text { consumption } \\
\text { (servings per day) }\end{array}$} & \multicolumn{2}{|c|}{$\begin{array}{l}\text { Carotenoid } \\
\text { intake } \\
(\mu \mathrm{g} / \text { day })^{\mathrm{e}}\end{array}$} \\
\hline & & & Never & Past & Current & $<15$ & $\geq 35$ & & & $\begin{array}{c}\text { At } \\
\text { home }\end{array}$ & $\begin{array}{c}\text { At } \\
\text { work }\end{array}$ & Fruit & Vegetable & $\begin{array}{l}\text { Alpha } \\
\text { carotene }\end{array}$ & $\begin{array}{l}\text { Lyco- } \\
\text { pene }\end{array}$ \\
\hline 0 years & 61546 & 50.4 & 45.2 & 31.2 & 23.6 & 31.1 & 9.9 & 170 & 19.8 & 24.1 & 31.3 & 2.1 & 3.0 & 714 & 9004 \\
\hline$<5$ years & 17822 & 52.1 & 41.9 & 32.6 & 25.5 & 31.7 & 10.4 & 169 & 19.9 & 26.4 & 33.9 & 2.1 & 3.2 & 728 & 9285 \\
\hline $5-14$ years & 4504 & 51.0 & 39.1 & 33.5 & 27.5 & 31.0 & 9.0 & 165 & 19.9 & 27.8 & 43.0 & 2.1 & 3.2 & 713 & 9370 \\
\hline$\geq 15$ years & 2875 & 52.0 & 41.3 & 29.9 & 28.8 & 33.9 & 8.8 & 160 & 20.0 & 32.9 & 63.0 & 2.0 & 3.1 & 670 & 9161 \\
\hline
\end{tabular}

a The values have been directly standardized according to the age distribution of the entire Nurses' Health Study cohort in 1984, using six age categories $(<40,40-44,45-49,50-54,55-59, \geq 60$ years). Data are means unless otherwise noted.

b Quantity smoked is for current smokers only.

${ }^{c}$ Months since quitting is for past smokers only.

d Current regular exposure in 1982.

e Adjusted for total energy intake. 
on exposure at work. For the covariates other than personal smoking history, we included a missing indicator variable in the model for each covariate to designate whether the value was missing for that questionnaire cycle. Women with a missing value for age of smoking onset were assigned the median value of 19 years. For the other smoking variables, we carried forward information from the previous questionnaire cycle whenever reasonable, and otherwise excluded the person-time with missing smoking data.

We performed all statistical analyses using SAS version 8.2 (SAS Institute Inc, Cary, NC, USA). The Institutional Review Board of Brigham and Women's Hospital in Boston approved both the Nurses' Health Study and this analysis, and all of the study participants provided implied consent by completing and returning the baseline questionnaire.

\section{Results}

During 16 years and 1261405 person-years of followup from 1984 to 2000, there were 859 confirmed cases of lung cancer diagnosed. Table 1 shows the baseline characteristics of the 86747 women included in the primary analysis, categorized by the number of years of prior operating room work reported in $1984(0,<5$, $5-14$, and $\geq 15$ years). In 1984, 25201 women (29\%) reported a history of prior operating room work. Overall, the baseline characteristics were similar across the categories of duration of prior operating room employment. The percentage of women reporting regular exposure to passive smoke in 1982 increased as the duration of operating room employment increased. Exposure to passive smoke in the work environment was particularly variable across the categories of duration of operating room employment, possibly due to the unavailability of nonsmoking break rooms in 1982 for operating room nurses wearing surgical scrubs. In addition, the percentage of women who were current smokers increased as the duration of operating room employment increased, and the nurses with no history of prior operating room work were generally younger than those with a history of operating room employment.

We found no significant increase in the rate of lung cancer to be associated with prior operating room work, when compared with the rate for no prior operating room employment, for any of the categories of duration of prior operating room work reported in 1984 (table 2). In fact, the nurses who reported $\geq 15$ years of prior employment in an operating room had a significantly lower risk of lung cancer than women with no prior operating room employment [rate ratio (RR) $0.58,95 \%$ confidence interval (95\% CI) 0.37-0.91]. These results were unchanged when we adjusted for smoking history using pack-years of smoking, rather than years since quitting among past smokers and cigarettes smoked per day among current smokers. We did not find any significant association between operating room employment and lung cancer incidence in analyses using other exposure categorizations. In the analyses with binary exposure categorizations, the multivariable-adjusted rate ratios were 0.87 (95\% CI 0.56-1.34) for current operating room work in 1982, 0.99 (95\% CI 0.86-1.15) for any history of prior operating room work reported in 1984, and 0.98 (95\% CI $0.85-1.13$ ) for any current or prior operating room work reported in 1982, 1984, or 1992. We did not have sufficient power to evaluate the association between current operating room work in 1992 and lung cancer incidence, although there was no suggestion of an increased rate of lung cancer among women working in the operating room in 1992 (results not shown).

In all of the analyses, the changes between the ageadjusted and multivariable-adjusted rate ratios were modest, and these changes were almost entirely due to control for smoking history. Smoking was strongly associated with lung cancer risk in our multivariable-adjusted analyses, with incidence rate ratios of 9.7 (95\% I 7.2-13.0) for past smokers with $<5$ years since quitting and 32.7 (95\% CI 17.1-62.6) for current smokers of $\geq 45$ cigarettes per day. We examined changes in smoking status over time among the women with 0 years, $<5$ years, and $\geq 5$ years of operating room employment in 1984 to evaluate the potential for time-dependent confounding by smoking status (30). Although there

Table 2. Incidence rate ratios (RR) of lung cancer by number of years of operating room work reported in 1984 by the Nurses' Health Study cohort. $(95 \% \mathrm{Cl}=95 \%$ confidence interval, ref $=$ reference)

\begin{tabular}{|c|c|c|c|c|c|c|}
\hline \multirow{2}{*}{$\begin{array}{l}\text { Prior } \\
\text { operating } \\
\text { room work }\end{array}$} & \multirow{2}{*}{$\begin{array}{l}\text { Number } \\
\text { of } \\
\text { cases }\end{array}$} & \multirow{2}{*}{$\begin{array}{l}\text { Person- } \\
\text { years }\end{array}$} & \multicolumn{2}{|c|}{ Age-adjusted } & \multicolumn{2}{|c|}{ Multivariable } \\
\hline & & & $\mathrm{RR}$ & $95 \% \mathrm{Cl}$ & $\mathrm{RR}^{\mathrm{a}}$ & $95 \% \mathrm{Cl}^{\mathrm{a}}$ \\
\hline $\begin{array}{l}\text { None } \\
<1 \text { year in }\end{array}$ & 577 & 897838 & 1.00 & ref & 1.00 & ref \\
\hline operating room & 96 & 126622 & 1.03 & $0.83-1.28$ & 1.01 & $0.81-1.25$ \\
\hline $\begin{array}{l}1-4 \text { years in } \\
\text { operating room } \\
5-9 \text { years in }\end{array}$ & 111 & 130459 & 1.13 & $0.92-1.38$ & 1.08 & $0.88-1.32$ \\
\hline $\begin{array}{l}\text { operating room } \\
10-14 \text { vears in }\end{array}$ & 38 & 42793 & 1.27 & $0.92-1.77$ & 1.18 & $0.84-1.64$ \\
\hline $\begin{array}{l}\text { operating room } \\
\geq 15 \text { years in }\end{array}$ & 17 & 22379 & 1.06 & $0.64-1.74$ & 0.92 & $0.55-1.51$ \\
\hline operating room & 20 & 41314 & 0.66 & $0.42-1.04$ & 0.58 & $0.37-0.91$ \\
\hline $\mathrm{P}$ for trend & & & & 0.49 & & 0.11 \\
\hline
\end{tabular}

${ }^{a}$ Adjusted for age in months, smoking status (never, past, current), years since quitting for past smokers $(<5,5-14, \geq 15$ years), cigarettes smoked/ day for current smokers $(1-4,5-14,15-24,25-34,35-44$, $\geq 45$ cigarettes), age of smoking onset in years, passive exposure to cigarette smoke at home or work (no, occasionally, regularly), quintiles of fruit and vegetable consumption, and quintiles of carotenoid (alpha carotene and lycopene) intake. 
Table 3. Incidence rate ratios (RR) for lung cancer among never smokers and past smokers with $\geq 10$ years since quitting. (95\% $\mathrm{Cl}=95 \%$ confidence interval, ref $=$ reference)

\begin{tabular}{|c|c|c|c|c|c|c|}
\hline \multirow{2}{*}{$\begin{array}{l}\text { Prior } \\
\text { operating- } \\
\text { room work }\end{array}$} & \multirow{2}{*}{$\begin{array}{l}\text { Number } \\
\text { of } \\
\text { cases }\end{array}$} & \multirow{2}{*}{$\begin{array}{l}\text { Person- } \\
\text { years }\end{array}$} & \multicolumn{2}{|c|}{ Age-adjusted } & \multicolumn{2}{|c|}{ Multivariable } \\
\hline & & & $\mathrm{RR}$ & $95 \% \mathrm{Cl}$ & $\mathrm{RR}^{\mathrm{a}}$ & $95 \% \mathrm{Cl}^{\mathrm{a}}$ \\
\hline $\begin{array}{l}\text { None } \\
<1 \text { vear in }\end{array}$ & 164 & 642894 & 1.00 & ref & 1.00 & ref \\
\hline operating room & 26 & 88140 & 1.00 & $0.66-1.51$ & 0.99 & $0.65-1.51$ \\
\hline $\begin{array}{l}1-4 \text { years in } \\
\text { operating room }\end{array}$ & 26 & 89969 & 0.92 & $0.61-1.40$ & 0.90 & $0.59-1.37$ \\
\hline $\begin{array}{l}5-14 \text { years in } \\
\text { operating room } \\
\geq 15 \text { years in }\end{array}$ & b & 43923 & 0.80 & $0.42-1.53$ & 0.76 & $0.40-1.45$ \\
\hline operating room & 5 & 27373 & 0.63 & $0.26-1.54$ & 0.63 & $0.26-1.53$ \\
\hline$P$ for trend & & & & 0.22 & & 0.18 \\
\hline
\end{tabular}

a Adjusted for age in months, smoking status (never, past), age of smoking onset in years, passive exposure to cigarette smoke at home or work (no, occasionally, regularly), quintiles of fruit and vegetable consumption, and quintiles of carotenoid (alpha carotene and lycopene) intake.

${ }^{b}$ Exposure categories for $5-9$ years and $10-14$ years in an operating room were combined to increase the stability of the estimates.

were differences in smoking status between these three exposure groups at baseline, the changes in smoking status over time were similar for the three groups. This finding suggests that any bias due to the use of timevarying covariates to control for smoking was minimal (results not shown). Additional information on the association between smoking history and lung cancer incidence in the Nurses' Health Study cohort is available elsewhere (31).

Our findings were similar when evaluated within strata of smoking status (never smokers, past smokers, current smokers). The analysis restricted to never smokers had limited power due to the small number of never smokers with lung cancer $(\mathrm{N}=87)$. We therefore conducted an analysis restricted to never smokers and past smokers with at least 10 years since quitting, since the risk of lung cancer for past smokers approaches the risk of never smokers 10 to 15 years after quitting (32). This analysis, which included 231 cases of lung cancer, did not suggest any change in the rate of lung cancer among women with a history of prior operating room work in a comparison with women who had never worked in an operating room (table 3 ).

In another analysis with exposure classified as current operating room work in 1982, we excluded lung cancer cases diagnosed during the first 2 years of follow-up because the presence of preclinical disease may have affected employment status in 1982 for these cases. The point estimate for this analysis was still nonsignificant and was slightly attenuated (RR 0.95, 95\% CI 0.61-1.48) when compared with the result of the analysis including all of the cases. The association between operating room employment and lung cancer did not vary substantially by histological type, although there was a limited number of cases in several disease subgroups (results not shown). Finally, in an analysis by current employment status in 1982 (operating room nursing, in-patient nursing, out-patient or community nursing, other nursing, nonnursing employment, or homemaker), we did not find a significant difference in the rate of lung cancer for women in any category of employment in a comparison with women who were nursing educators (results not shown).

\section{Discussion}

The results of this prospective study indicate that employment as an operating room nurse, an indirect measure of surgical smoke exposure, does not increase the rate of lung cancer. In fact, our findings suggest that nurses with the longest history of operating room work, and presumably the greatest exposure to surgical smoke, have a decreased risk of lung cancer.

To our knowledge, this study is the first population-based analysis of the health effects of operating room employment as a measure of exposure to surgical smoke. However, there are numerous laboratory and animal studies of surgical smoke. Chemical composition studies have detected the presence of several potentially hazardous substances in surgical smoke, including known human carcinogens such as benzene, formaldehyde, and PAH $(1,3)$. Kokosa \& Eugene (1) reported that irradiation of $50 \mathrm{mg}$ of beef liver with a carbon dioxide laser produced $12.8 \mu \mathrm{g}$ of benzene, $4.3 \mu \mathrm{g}$ of acrolein, $3.6 \mu \mathrm{g}$ of PAH, and $3.4 \mu \mathrm{g}$ of formaldehyde. Although these levels are low, the authors estimated that irradiation of 3 grams of tissue in the absence of a smoke evacuation system would produce enough of these chemicals to exceed the OSHA safety limits (1). In a similar study, Sagar et al (3) detected maximum levels of $71 \mu \mathrm{g} / \mathrm{m}^{3}$ of benzene and $460 \mu \mathrm{g} / \mathrm{m}^{3}$ of toluene in electrocautery smoke produced during colorectal surgery, in the absence of a smoke evacuation device. Other laboratory studies have demonstrated that smoke from both electrocautery and laser surgery is mutagenic to certain strains of Salmonella typhimurium $(16,17)$. Animal studies have shown that repeated exposure to high levels of surgical smoke can induce inflammatory pulmonary changes, including emphysema and bronchiolitis (18-21). Despite these laboratory and animal data, there are no population-based studies available to suggest whether or not repeated exposure to surgical smoke can induce carcinogenesis or chronic inflammation in humans.

Our results indicate a significant $42 \%$ lower rate of lung cancer among women with the longest history of operating room employment. One potential explanation 
for this finding is that women who are able to continue working in an operating room for $\geq 15$ years may be less susceptible to the short-term effects of surgical smoke, such as headaches and upper respiratory irritation, or are in better overall health than women who work in the operating room for shorter periods of time or women who work in other nursing fields. Alternatively, nurses with $\geq 15$ years of employment in an operating room may differ with respect to certain lifestyle factors or behavior in comparison with nurses with a shorter duration of operating room work and women in other nursing fields. When we evaluated educational status and husband's education, as measures of socioeconomic status, we did not observe any differences that could help to explain the inverse association between long-term employment in an operating room and lung cancer incidence. Another potential explanation for this finding is residual confounding due to smoking history. Although we carefully controlled for smoking history, there could be differences in smoking between categories of duration of operating room employment that were not adequately captured by the smoking characteristics for which we controlled. In addition, prior to bans on smoking in hospitals, the amount or duration of exposure to second-hand smoke may have differed for operating room nurses and women working in other nursing fields. Controlling for current exposure to cigarette smoke in the work environment in 1982 did not affect our results, although this measure may not have adequately captured levels of passive smoke exposure in the work environment prior to 1982. Finally, we cannot rule out the possible contribution of chance with respect to this finding.

In addition to potential confounding by overall health status or residual confounding by smoking history, there are other limitations that may have affected our results. We do not have data on each nurse's actual exposure to surgical smoke, and we therefore used the number of years of operating room employment as a proxy exposure measure. Although we would expect surgical smoke exposure to be correlated with the number of years of operating room employment, our data do not account for potential variation between hospitals and changes over time in the frequency of smoke-producing surgical procedures or precautions to reduce exposure to surgical smoke. However, it would be nearly impossible to measure surgical smoke exposure accurately over extended periods of time in a large cohort; therefore, a proxy measure is the only feasible way to measure exposure to surgical smoke in a population-based study of this size. Another limitation of this analysis is the unavailability of information on each nurse's exposure to exhaled anesthetic gases and other potentially hazardous substances in the operating room. Although epidemiologic studies of the cancer risk of health professionals exposed to anesthetic gases have been inconsistent, there is evidence of a mutagenic effect of certain chemicals used as anesthetics prior to 1980 (33-35).

The duration of operating room employment was only requested on the 1984 questionnaire; therefore, we do not know the actual duration of employment for the women who continued working in an operating room after 1984. In 1984, the age range of women in this cohort was 38 to 63 years; therefore, it is possible that the younger nurses in our cohort may have continued working in an operating room for 10 or more additional years, or that nurses with no operating room employment in 1984 may have started working in an operating room after this point in time. However, the 1992 questionnaire collected information on current operating room employment, and an analysis comparing women with any history of operating room employment reported in 1982, 1984, or 1992 with women with no history of operating room employment did not suggest any difference in the rate of lung cancer. We also did not have information on the actual dates of operating room employment for each nurse. As a result, with the exception of nurses who reported current operating room work on the 1992 questionnaire, we do not know which nurses were still working in an operating room after the use of laser surgery became more common in the early 1980s and were therefore potentially exposed to laser surgery smoke. However, because of the widespread use of electrocautery dating back at least to the 1940s and 1950s, it is likely that all of the operating room nurses in our cohort were exposed to electrocautery smoke. Finally, it is possible that exposure to surgical smoke increases the risk of lung cancer, but the follow-up period in this study was not long enough to detect this increase in risk; however, this scenario is unlikely due to the decreased rate of lung cancer for the nurses with the longest history of operating room work.

This study has numerous strengths, including the size of the cohort and the large number of lung cancer cases, the high percentage of nurses with a history of operating room work, the long follow-up period, and the high percentage of follow-up information obtained. Because our data are prospective, there is no risk of differential recall between the cases and controls, and any misclassification in the exposure and covariate data should have been similar for both the cases and the noncases. We also collected extensive covariate data at multiple points in time, and the data for smoking history, the primary confounder in our analysis, are comprehensive. The uniqueness of our data on operating room employment and subsequent lung cancer development is a major strength of our study, since, without such data, it would be difficult to study the association between surgical smoke exposure and lung cancer risk prospectively. In addition, we would expect high accuracy in the reporting of operating room employment from this 
cohort of nurses, since our exposure measure relates to their nursing careers and the number of years spent in a particular nursing field.

According to the results of this prospective analysis, long-term operating room employment and the resulting exposure to surgical smoke does not appear to increase the risk of lung cancer. However, surgical smoke exposure may increase the risk of chronic pulmonary conditions other than lung cancer, such as asthma or pneumonia, and additional research is needed on the association between exposure to surgical smoke and these outcomes. Given the composition of surgical smoke and its mutagenic and inflammatory potential demonstrated in animal and laboratory studies, prudent practice dictates that precautions be taken to minimize the exposure of both surgical personnel and patients to surgical smoke.

\section{Acknowledgments}

This study was supported by research grant CA87969 and research training grants T32 CA09001 and R25 CA098566 from the National Cancer Institute, National Institutes of Health, and by additional funding from the Association of periOperative Registered Nurses.

We are grateful to the Nurses' Health Study participants for their dedication to the study and their contribution to this research.

\section{References}

1. Kokosa JM, Eugene J. Chemical composition of laser-tissue interaction smoke plume. J Laser Appl. 1989;1:59-63.

2. Hensman C, Baty D, Willis RG, Cuschieri A. Chemical composition of smoke produced by high-frequency electrosurgery in a closed gaseous environment: an in vitro study. Surg Endosc. 1998;12:1017-19.

3. Sagar PM, Meagher A, Sobczak S, Wolff BG. Chemical composition and potential hazards of electrocautery smoke. Br J Surg. 1996;83:1792.

4. Ott D. Smoke production and smoke reduction in endoscopic surgery: preliminary report. Endosc Surg Allied Technol. 1993;1:230-2.

5. Beebe DS, Swica H, Carlson N, Palahniuk RJ, Goodale RL. High levels of carbon monoxide are produced by electro-cautery of tissue during laparoscopic cholecystectomy. Anesth Analg. 1993;77:338-41.

6. Wu JS, Luttmann DR, Meininger TA, Soper NJ. Production and systemic absorption of toxic byproducts of tissue combustion during laparoscopic surgery. Surg Endosc. 1997;11:1075-9.

7. Wu JS, Monk T, Luttmann DR, Meininger TA, Soper NJ. Production and systemic absorption of toxic byproducts of tissue combustion during laparoscopic cholecystectomy. J Gastrointest Surg. 1998;2:399-405.
8. Ott DE. Carboxyhemoglobinemia due to peritoneal smoke absorption from laser tissue combustion at laparoscopy. J Clin Laser Med Surg. 1998;16:309-15.

9. Occupational Safety and Health Administration (OSHA). Safety and health topics: laser/electrosurgery plume. Washington (DC): OSHA; 2003 [accessed 2005 August 25]. Available from: http://www.osha.gov/SLTC/laserelectrosurgeryplume/ index.html.

10. Chen CC, Willeke K. Aerosol penetration through surgical masks. Am J Infect Control. 1992;20:177-84.

11. Kunachak S, Sobhon P. The potential alveolar hazard of carbon dioxide laser-induced smoke. J Med Assoc Thai. 1998;81:27882.

12. Weber A, Willeke K, Marchioni R, Myojo T, McKay R, Donnelly $\mathrm{J}$, et al. Aerosol penetration and leakage characteristics of masks used in the health care industry. Am J Infect Control. 1993;21:167-73.

13. National Institute for Occupational Safety and Health (NIOSH). Control of smoke from laser/electric surgical procedures. Washington (DC): NIOSH; 1998 [accessed 2005 August 25]. Available from: http://www.cdc.gov/niosh/hc11.html.

14. Smith JP, Moss CE, Bryant CJ, Fleeger AK. Evaluation of a smoke evacuator used for laser surgery. Lasers Surg Med. 1989;9:276-81.

15. Smith JP, Topmiller JL, Shulman S. Factors affecting emission collection by surgical smoke evacuators. Lasers Surg Med. 1990;10:224-33.

16. Tomita Y, Mihashi S, Nagata K, Ueda S, Fujiki M, Hirano M, et al. Mutagenicity of smoke condensates induced by $\mathrm{CO}_{2}$-laser irradiation and electrocauterization. Mutat Res. 1981;89:1459.

17. Gatti JE, Bryant CJ, Noone RB, Murphy JB. The mutagenicity of electrocautery smoke. Plastic Reconstr Surg. 1992;89:7814.

18. Baggish MS, Elbakry M. The effects of laser smoke on the lungs of rats. Am J Obstet Gynecol. 1987;156:1260-5.

19. Baggish MS, Baltoyannis P, Sze E. Protection of the rat lung from the harmful effects of laser smoke. Lasers Surg Med. 1988;8:248-53.

20. Freitag L, Chapman GA, Sielczak M, Ahmed A, Russin D. Laser smoke effect on the bronchial system. Lasers Surg Med. 1987;7:283-8.

21. Wenig BL, Stenson KM, Wenig BM, Tracey D. Effects of plume produced by the Nd:YAG laser and electrocautery on the respiratory system. Lasers Surg Med. 1993;13:242-5.

22. Rich-Edwards JW, Corsano KA, Stampfer MJ. Test of the National Death Index and Equifax Nationwide Death Search. Am J Epidemiol. 1994;140:1016-19.

23. Stampfer MJ, Willett WC, Speizer FE, Dysert DC, Lipnick $\mathrm{R}$, Rosner B, et al. Test of the National Death Index. Am J Epidemiol. 1984;119:837-9.

24. Salvini S, Hunter DJ, Sampson L, Stampfer MJ, Colditz GA, Rosner B, et al. Food-based validation of a dietary questionnaire: the effects of week-to-week variation in food consumption. Int J Epidemiol. 1989;18:858-67.

25. Michaud DS, Giovannucci EL, Ascherio A, Rimm EB, Forman MR, Sampson L, et al. Associations of plasma carotenoid concentrations and dietary intake of specific carotenoids in samples of two prospective cohort studies using a new carotenoid database. Cancer Epidemiol Biomarkers Prev. 1998;7:283-90.

26. Feskanich D, Ziegler RG, Michaud DS, Giovannucci EL, Speizer FE, Willett WC, et al. Prospective study of fruit and vegetable consumption and risk of lung cancer among men and 
women. J Natl Cancer Inst. 2000;92:1812-23.

27. Michaud DS, Feskanich D, Rimm EB, Colditz GA, Speizer FE, Willett WC, et al. Intake of specific carotenoids and risk of lung cancer in 2 prospective US cohorts. Am J Clin Nutr. 2000;72:990-7.

28. Cox DR, Oakes D. Analysis of survival data. London: Chapman and Hall; 1984.

29. Therneau TM. Extending the Cox model. In: Lin DY, Fleming TR, editors. Proceedings of the First Seattle Symposium in Biostatistics: survival analysis. New York (NY): Springer Verlag; 1997.

30. Greenland S. Introduction to regression models. In: Rothman KJ, Greenland S. Modern epidemiology. New York (NY): Lippincott Williams \& Wilkins; 1998. p 422-4.

31. Bain C, Feskanich D, Speizer FE, Thun M, Hertzmark E, Rosner BA, et al. Lung cancer rates in men and women with comparable histories of smoking. J Natl Cancer Inst. 2004;96:826-34.

32. Speizer FE, Colditz GA, Hunter DJ, Rosner B, Hennekens C. Prospective study of smoking, antioxidant intake, and lung cancer in middle-aged women (USA). Cancer Causes Control. 1999;10:475-82.

33. Edling C. Anesthetic gases as an occupational hazard-a review. Scand J Work Environ Health. 1980;6:85-93.

34. Babich H. Reproductive and carcinogenic health risks to hospital personnel from chemical exposure-a literature review. J Environ Health. 1985;48:52-6.

35. McGregor DG. Occupational exposure to trace concentrations of waste anesthetic gases. Mayo Clin Proc. 2000;75:273-7.

Received for publication: 20 March 2006 